Cahiers $d u$ MONDE RUSSE

\section{Cahiers du monde russe}

Russie - Empire russe - Union soviétique et États indépendants

$46 / 4 \mid 2005$

L'invention d'une politique humanitaire

\title{
Manon de Courten, History, Sophia and the Russian
}

Nation

André Filler

\section{OpenEdition}

\section{Journals}

Édition électronique

URL : https://journals.openedition.org/monderusse/6578

DOI : 10.4000/monderusse. 6578

ISSN : $1777-5388$

Éditeur

Éditions de l'EHESS

\section{Édition imprimée}

Date de publication : 1 décembre 2005

Pagination : 879-881

ISBN : 2-7132-2057-2

ISSN : $1252-6576$

Référence électronique

André Filler, «Manon de Courten, History, Sophia and the Russian Nation », Cahiers du monde russe [En ligne], 46/4 | 2005, mis en ligne le 29 juin 2009, consulté le 03 septembre 2022. URL : http:// journals.openedition.org/monderusse/6578; DOI : https://doi.org/10.4000/monderusse.6578

Ce document a été généré automatiquement le 3 septembre 2022

Tous droits réservés 


\title{
Manon de Courten, History, Sophia and the Russian Nation
}

\author{
André Filler
}

\section{RÉFÉRENCE}

Manon de COURTEN, History, Sophia and the Russian Nation. A Reassessment of Vladimir Solov'ëv's Views on History and his Social Commitment.Berne : Peter Lang, 2004, $532 \mathrm{p}$.

1 Philosophe majeur (le seul russe de son temps à laisser l'ébauche d'un véritable système de pensée), écrivain inspiré, brillant polémiste, acteur public de premier plan, Vladimir Solov 'ëv reste avant tout un personnage authentiquement sympathique par son anticonformisme, sa liberté intellectuelle et son engagement humaniste, si peu pratiqués par ses compatriotes et contemporains. Il est donc naturel que les chercheurs, tout comme les lecteurs, tombent souvent sous le charme de son profil insolite : l'œuvre de Solov'ëv donne envie d'être lue et analysée, ne serait-ce que pour le plaisir de passer quelque temps dans la délicieuse compagnie de son auteur.

De cette pensée aussi riche et fertile qu'hétéroclite et décousue, Manon de Courten a choisi pour son essai - dont le principal mérite serait l'indépendance de l'analyse appliquée à un terrain cependant plus que défriché (il suffit de rappeler les travaux désormais classiques de K. Močul'skij, L. Müller, A. Besançon, A. Walicki) - un aspect bien particulier: les rapports entre Solov'ëv et l'histoire. Ni philosophe de l'histoire à proprement parler, ni historien professionnel, Solov'ëv perçoit tout développement historique à travers le prisme de ses propres constructions philosophiques et théologiques, parmi lesquelles le concept de la Sophia, sagesse divine transcendantale, occupe une place centrale.

3 L'interdisciplinarité affichée de l'auteur élargit singulièrement son propos, qui peut paraître de prime abord tout à fait circonscrit. L'étude de Manon de Courten, qui tente d'embrasser l'ensemble d'une thématique complexe, suit ainsi deux axes parallèles. D'un 
côté, elle élabore un cadre théorique cohérent afin d'éclairer les liens entre le Solov'ëv philosophe et le Solov'ëv historien (ou, plutôt, visionnaire de l'histoire). Cette exégèse est développée dans la première partie de l'ouvrage. De l'autre, elle se penche sur l'action sociétale de Solov'ëv, dictée, selon elle, par ses conceptions théoriques.

L'auteur fait une distinction, particulièrement pertinente pour l'œuvre du philosophe, entre la théologie de l'histoire et la philosophie de l'histoire. La première est augustinienne dans ses sources et répond avant tout au questionnement métaphysique : « Pourquoi Dieu a-t-il créé l'histoire? ». La seconde puise son inspiration chez Hegel et sa quête tente de trouver une raison derrière l'évolution historique universelle. Solov'ëv contribue aux deux courants en plaçant les considérations sur l'histoire au centre de son œuvre, sans pour autant y consacrer un texte spécifique. Manon de Courten arrive ainsi avec succès à identifier, au fil de ses lectures, de nombreux passages épars provenant de différents ouvrages du penseur (entre autres, Istorija $i$ buduščnost' teokratii, Opravdanie dobra, Čtenija o bogočelovčestve, Filosofskie načala cel'nogo znanija $a^{1}$ parmi les ouvrages russes; La Russie et l'Église universelle, Sophia, composés en français, mais aussi une remarquable série d'articles rédigés pour l'encyclopédie de Brockhaus-Efron), et ainsi à (re)construire la vision solovievienne de l'histoire dans son ensemble.

Un des éléments les plus intéressants de cette partie de l'ouvrage est l'étude approfondie des influences. Car, paradoxalement, le plus autonome des philosophes russes reste lourdement endetté envers la pensée occidentale. Certains de ses maîtres à penser sont communément connus et admis comme tels, par exemple Maxime le Confesseur, chez qui il emprunte l'affirmation du libre arbitre humain chez le Christ et l'évaluation positive du papisme (prise de position courageuse venant de l'ancien admirateur des slavophiles). Ou Auguste Comte, dont il utilise le schéma tripartite du processus historique (étape théologique, étape métaphysique, étape positive). D'autres le sont bien moins : l'auteur propose ainsi une comparaison convaincante entre la vision historique de Solov'ëv et celle d'Origène, pourtant rarement cité de manière explicite par le penseur russe, sinon dans les passages critiques. Or, c'est précisément chez Origène que Solov'ëv trouve le concept (qu'il modifie par la suite) d'apokatastasis, "restauration » de tout être vivant en Dieu, but ultime du processus historique. Une influence d'un tout autre ordre est celle de son père, le grand historien Sergej Solov'ëv. S'appuyant sur les recherches précédentes, notamment sur les travaux de J. Sternkopf, Manon de Courten constate l'ascendant significatif des idées du père sur le fils dans des questions telles que le développement organique de la société, la vision libérale de l'occident, l'importance de l'État, enfin le rôle de Pierre le Grand dans l'histoire russe. Cependant, elle précise que la "théologisation» de l'histoire pratiquée par le fils aurait été incontestablement réfutée par le père, pour avoir trop négligé l'aspect empirique du réel historique.

6 L'auteur conclut la première partie de l'ouvrage par la présentation de cette nouvelle discipline, solovievienne par excellence, qu'est la "sophiologie de l'histoire", compromis astucieux entre la théologie historique, dominée par la transcendance divine, et la philosophie historique, qui traite (souvent délibérément) avec indifférence toute instance transcendante. Selon Solov'ëv, l'histoire est organisée autour des révélations de la Sophia, incarnation de l'union entre l'humain et le divin. Métaphoriquement, elle est représentée sous les traits d'une hypostase féminine de la sagesse divine (représentation qu'il doit en grande partie à ses études du judaïsme, et notamment de la Kabbale). En même temps, la Sophia possède les caractéristiques de l'âme universelle schellingienne. La Sophia apparaît trois fois dans l'histoire. La 
première apparition, « cosmogonique », se déroule quand l'unité divine primordiale se mue en création des formes organiques complexes. La deuxième, "mythologique ", voit l'humanité se transformer en un organisme muni de conscience intérieure. Et enfin la troisième, "historique ", est marquée par la naissance du Christ, dont le message universalise la Sophia, désormais matérialisée par l'Église, unie au-delà des divergences confessionnelles.

Comme tant d'autres, Solov'ëv accorde à la Russie une place de choix dans sa vision historique. La Russie peut, selon lui, devenir l'incarnation de la Sophia. Mais, contrairement aux slavophiles (toutes générations confondues), qui assouvissaient leurs penchants millénaristes dans la Russie contemporaine, prise telle quelle, Solov'ëv croit en une vocation russe potentielle, mais lointaine. Afin de se rapprocher des échéances eschatologiques et se rendre prête à sa grande mission, la société russe doit subir un nombre important de réformes. Solov'ëv va lui-même œuvrer dans ce sens, en endossant les habits lourds de la « conscience de la Russie » (comme le note judicieusement Manon de Courten, peu de ses contemporains lui reconnaissaient d'ailleurs cette qualité).

8 Ce dernier aspect du personnage est étudié dans la seconde partie de l'ouvrage, consacrée à des études de cas. L'auteur en choisit cinq : le meurtre du tsar Alexandre II, la famine de 1891-1892 et les rapports entre la société russe et les minorités religieuses (vieux-croyants) ou "national-religieuses» (Juifs, Polonais). Dans le premier, en appelant le successeur du monarque assassiné à faire preuve de clémence à l'endroit des meurtriers de son père, Solov'ëv tente, selon l'auteur, d'élever le débat, en le plaçant dans la perspective de l'éthique chrétienne, ce qui transforme une controverse politique en une quête métaphysique. Dans le cas de la famine, nous rencontrons le Solov'ëv militant, faisant montre d'une certaine compétence dans le domaine économique et d'une intuition remarquable quant aux origines écologiques du désastre. Ce cas précis est relativement peu étudié, et la place importante que lui accorde Manon de Courten comble un vide dans la recherche consacrée à l'œuvre du philosophe. En revanche, les trois cas des minorités ont déjà été abondamment décrits (surtout celui sur la question juive). Leur analyse amène toutefois l'auteur à une conclusion quelque peu inattendue : le courageux engagement "libéral» de Solov'ëv (auquel nous devons un de ses meilleurs textes, Rossija i nacional'nyj vopros ${ }^{2}$ ) serait avant tout, malgré toute sa sincérité, une manière d'instrumentaliser le débat sociétal afin de l'exploiter à ses propres desseins, à savoir l'accomplissement de l'idéal théocratique.

9 Les quelques réserves que provoque la lecture de l'ouvrage de Manon de Courten concernent davantage la forme que le contenu. Ainsi ses dimensions monumentales, appropriées pour la thèse dont il est issu, paraissent légèrement écrasantes pour un essai. La structure un peu rigide en sert sans doute bien le propos, tout en laissant désirer un narratif plus souple. Enfin, dans la mesure où l'auteur analyse l'œuvre de Solov'ëv par thèmes, et non par périodes, et s'évertue à donner une image totale de sa vision de l'histoire, le lecteur a l'impression que les contradictions intrinsèques au cheminement intellectuel mouvementé du philosophe semblent trop tamisées (malgré des tables comparatives qui décrivent les changements notables de sa Weltanschauung au fil des ans). De même, l'influence de l'extravagante "sophiologie» de l'histoire élaborée par Solov'ëv sur son action militante et son engagement social, pourtant très concrets, aurait pu être étayée davantage. Ceci étant, l'étude de Manon de Courten, grâce à un travail impressionnant sur la genèse épistémologique de l'œuvre, à une lecture précise et originale des textes, et surtout à la démarche qui consiste à examiner 
aussi bien la pensée que l'action, qui se complètent et se reflètent, pose un jalon de taille dans la recherche actuelle sur celui qui fut le plus inclassable des grands penseurs russes.

\section{NOTES}

1. Histoire et avenir de la théocratie, Justification du bien, Leçons sur la divino-humanité, Principes philosophiques de la connaissance intégrale.

2. La Russie et la question nationale. 